\title{
THE NATURE OF THE ACTION OF INTRAVENOUS ALDOSTERONE: EVIDENCE FOR A ROLE OF THE HORMONE IN URINARY DILUTION *
}

\author{
By EDMUND H. SONNENBLICK, † PAUL J. CANNON and JOHN H. LARAGH \\ (From the Department of Medicine, College of Physicians and Surgeons, Columbia Unizersity, \\ and the Presbyterian Hospital, Nez' York, N. Y.)
}

(Submitted for publication September 15, 1960; accepted January 13, 1961)

Aldosterone increases the renal retention of sodium chloride and promotes the excretion of potassium ions (1-11); but where and how the hormone acts in the renal tubule is poorly understood. The present study was designed to characterize further the mode and site of action of aldosterone in the nephron.

Information can be obtained about the site of action of a compound by observing its effect on free water formation (12). According to a current concept of renal physiology (13), reabsorption of solute (sodium chloride) is isosmotic in the proximal tubule (14), whereas, in the more distal segments, reabsorption may or may not be isosmotic $(15,16)$. During water diuresis (absence of antidiuretic hormone) the distal reabsorption of solute is selective, i.e., occurs without isosmotic amounts of water, leaving "solute-free" water behind for excretion (17). Thus, by determining the effect of a compound on solute excretion and on free water formation during maintained water diuresis, information may be obtained about its site of action (12). If aldosterone were to act to promote isosmotic reabsorption of sodium, the consequent reduction in solute excretion would be accompanied by a fall in urine flow and no change or fall in free water excretion. However, if aldosterone acts only at a more distal site, where reabsorption is selective, the reduced sodium excretion would be accompanied by no change in urine flow and hence, by a rise in free water excretion.

In the present study it has been shown that aldosterone can promote abstraction of sodium chloride exclusive of water from the tubular urine.

* This work was supported by the United States Public Health Service (Grant H-1275) and by Mrs. R. C. duPont.

$\dagger$ Present address: National Heart Institute, Bethesda, Md.
This action takes place in the tubule at a locus distal to that of isosmotic reabsorption. Also, this effect of the hormone on sodium chloride reabsorption appears to be dissociated from the effect on potassium excretion.

\section{EXPERIMENTAL}

Seven studies were performed on 3 subjects without evidence of renal or cardiovascular disease. Four of the experiments were done with subjects maintained on a normal $\mathrm{NaCl}$ intake (4 to $6 \mathrm{~g} \mathrm{NaCl}$ per day for 7 days), two with the subjects on a higher intake of salt for 7 days ( 8 to $20 \mathrm{~g} \mathrm{NaCl}$ per day), and one after drastic salt deprivation (less than $250 \mathrm{mg}$ per day for 6 days). In two subjects on normal salt intake, control studies of similar protocol but without administration of aldosterone were performed. All experiments were conducted in the fasting state at the same early morning hour with the subjects in a recumbent position.

Water diuresis was induced by having the patient ingest about $1,500 \mathrm{ml}$ of water by mouth during the hour before the experiment and was subsequently maintained by intravenous infusion of 5 per cent dextrose and water at a constant rate, at least $2 \mathrm{ml}$ per minute greater than urinary output. Adequate control periods were obtained until a steady state of maximum urine flow was demonstrated, so that any subsequent change in free water clearance could not be attributed to an increasing water diuresis.

When a steady state of maximum water diuresis had been achieved, $1 \mathrm{mg}$ of $d, l$-aldosterone monoacetate in $10 \mathrm{ml}$ of 10 per cent ethanol was administered intravenously. ${ }^{1}$ This was followed by another $1 \mathrm{mg}$ given in the dextrose and water infusion over the next hour. After the aldosterone administration was complete, the infusion of dextrose and water was continued at a constant rate.

Blood samples were taken via an indwelling heparinized needle and urine collections were made with an indwelling catheter except in Subjects S.H. and M.U., young males in whom adequate voluntary bladder emptying was possible at high rates of urine flow.

${ }^{1} d, l$-Aldosterone monoacetate, $1,000 \mu \mathrm{g}$ equivalent to $500 \mu \mathrm{g}$ active $d$-aldosterone supplied by Ciba Pharmaceutical Products, Summit, N. J. 


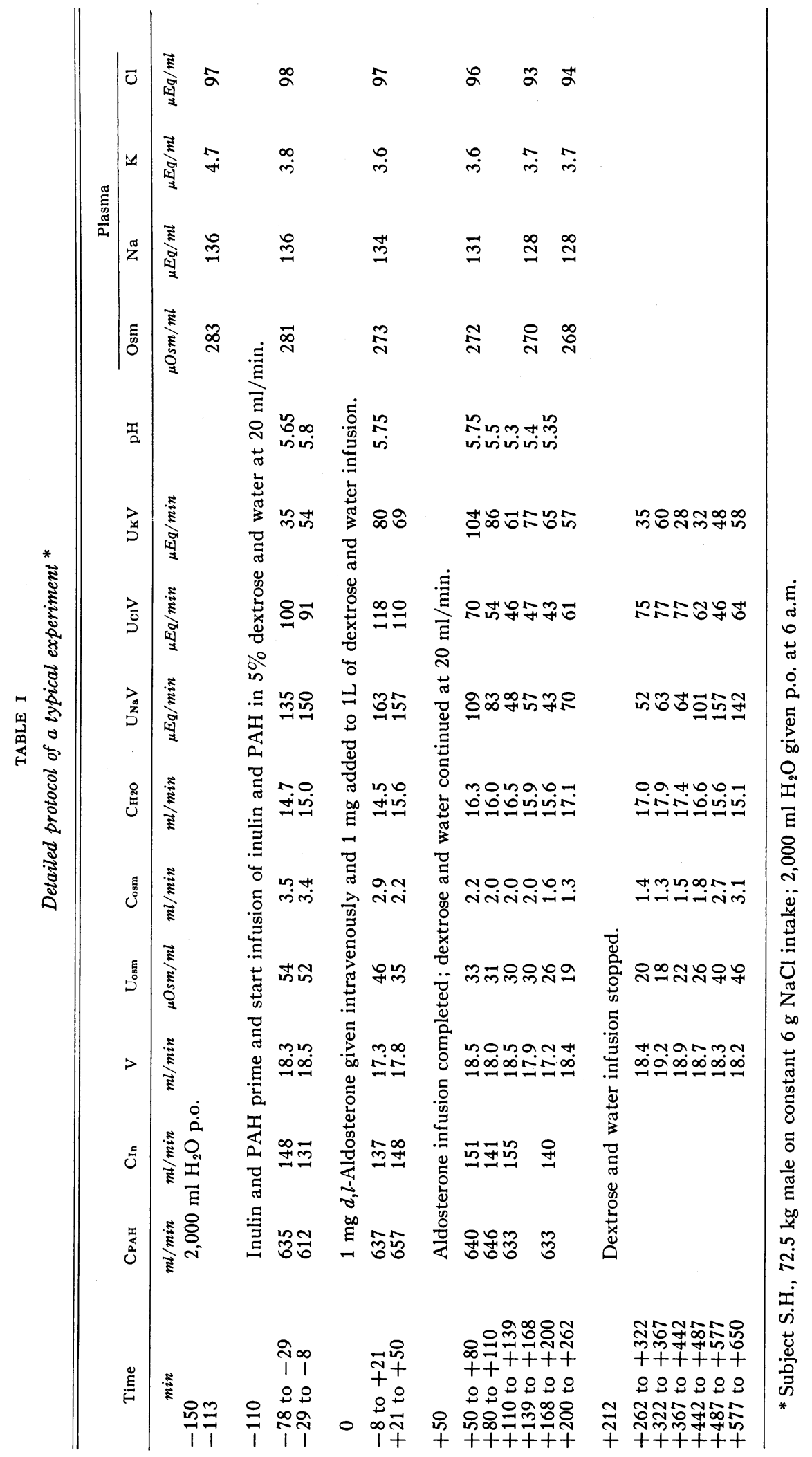


Plasma and urine samples were analyzed for inulin or creatinine, para-aminohippuric acid, and sodium, potassium and chloride, by methods previously described (12). The urinary $\mathrm{pH}$ was measured by a Beckman $\mathrm{pH}$ meter on freshly voided samples and the urine and plasma urea concentrations were determined by a modification of the urease method of Van Slyke and Cullen (18). The urine and plasma total solute concentration was measured with a Fiske osmometer.

Calculations. As indicated by Smith (13) and by Wesson and Anslow (17), urine can be divided into two moieties: the osmolar clearance $\left(\mathrm{C}_{\mathrm{os}} \dot{\mathrm{m}}\right)$, the volume of water necessary to contain the urinary solutes in a solution isosmotic with the plasma $\left(\mathrm{C}_{\text {osm }}=\mathrm{UV}_{\text {osm }} / \mathrm{P}_{\text {osm }}\right)$; and the free water clearance $\left(\mathrm{C}_{\mathrm{H}_{2} \mathrm{O}}\right)$, the net excess or deficit of water beyond the osmolar clearance. During water diuresis the free water clearance is a positive value and is calculated as $\mathrm{C}_{\mathrm{H}_{2} \mathrm{O}}=\mathrm{V}-\mathrm{U}_{\mathrm{osm}} \mathrm{V} / \mathrm{P}_{\mathrm{osm}}$, where $\mathrm{V}$ is the urine flow in milliliters per minute and $U_{o s m}$ and $\mathrm{P}_{\mathrm{os} m}$ are the solute concentrations of urine and of plasma in milliosmoles per kilogram of water.

\section{RESULTS}

The results of these experiments are summarized in Tables I, II and III and in Figures 1 through 4. In Table III, a typical control protocol is given. In Table $I$ the complete protocol of one experiment is given, and in Figure 1 the com-

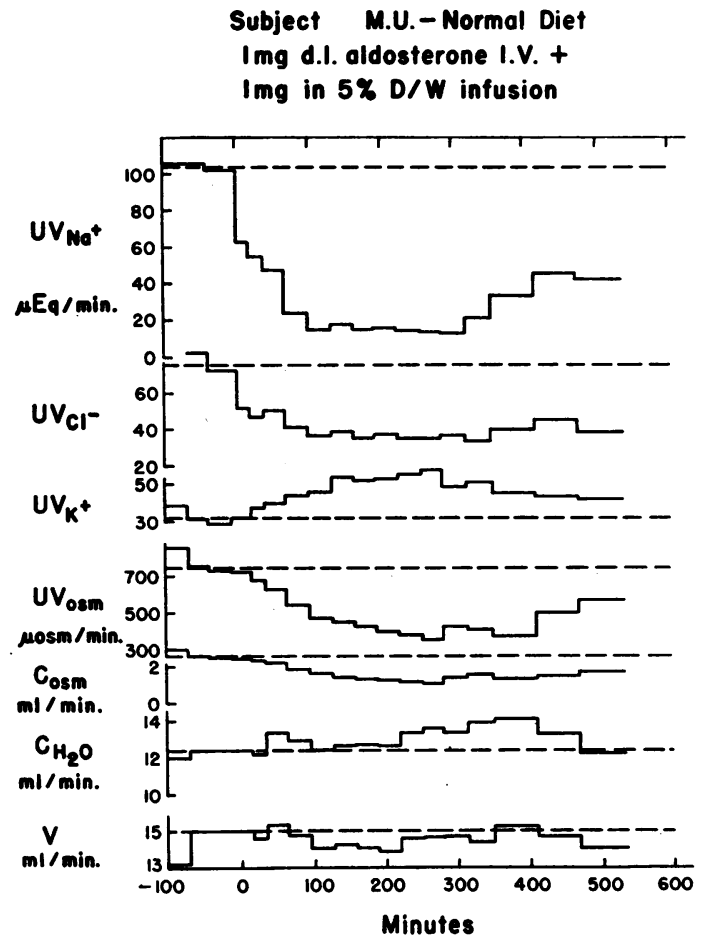

Fig. 1. Graph of the results of a Representative CLEARANCE STUdy (SEE TEXT).

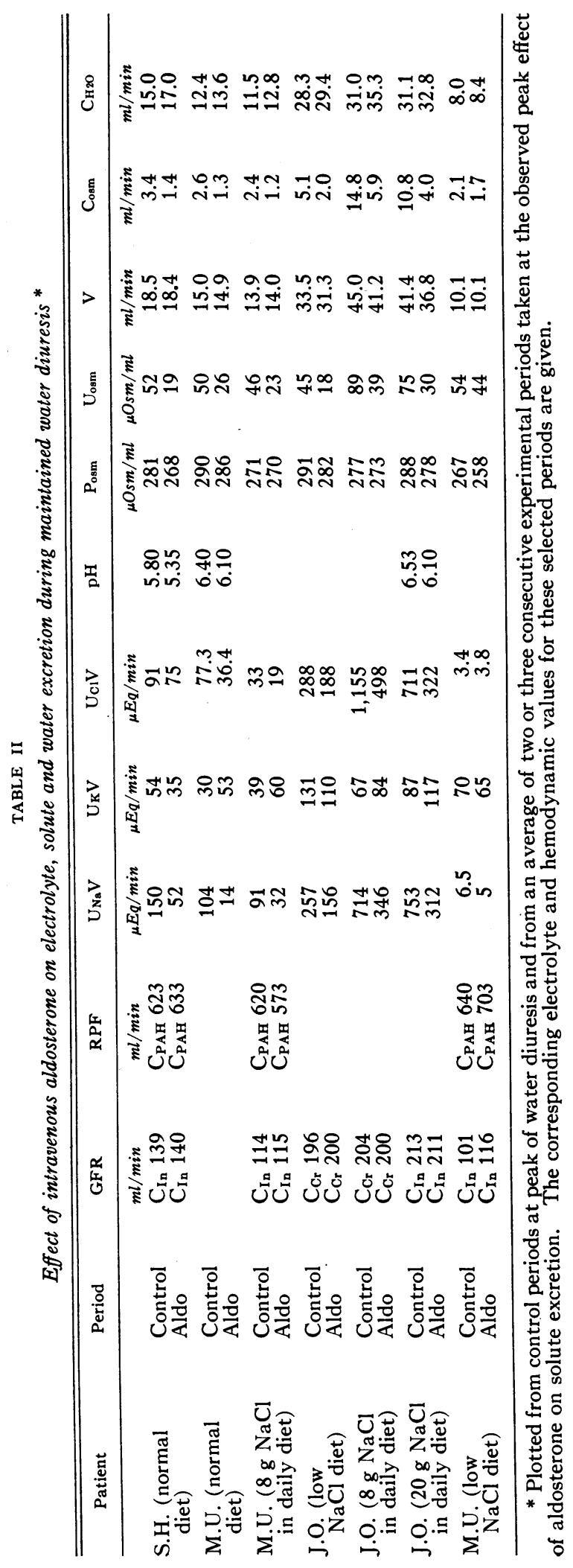




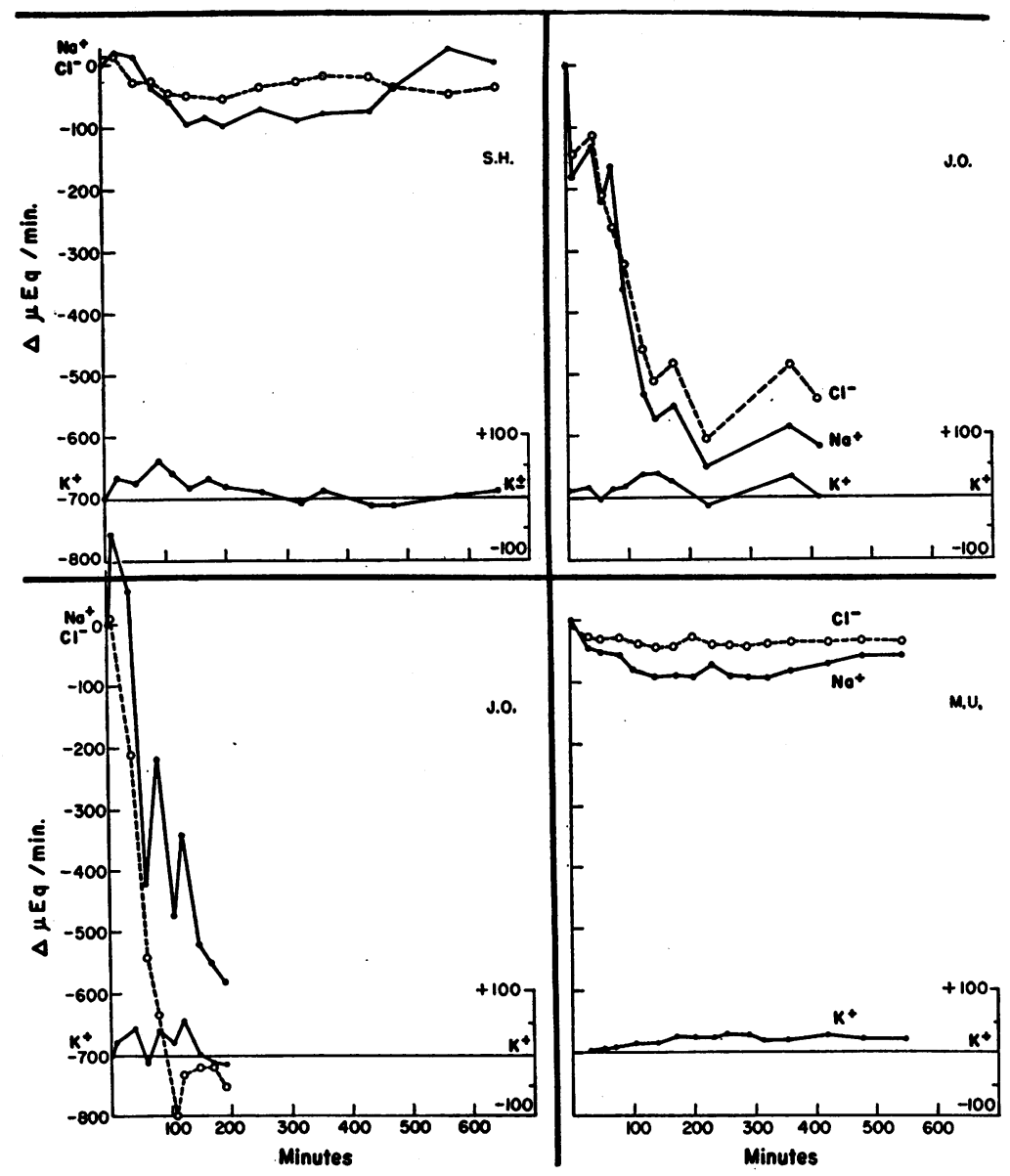

Fig. 2. EFfECt of ALdOSTERONE ON SODIUM, POTASSIUM AND CHLORIDE EXCRETION PLOTTED AGAINST TIME IN FOUR DIFFERENT STUdies. On the ordinates the net changes from the control values are plotted for each collection period. The increased potassium excretion is often out of phase with the reduction in sodium chloride excretion. Also the increase in potassium excretion is of considerably lesser magnitude than the reduction in sodium chloride excretion (see text).

plete results of another experiment are depicted graphically.

Effect on renal hemodynamics. Aldosterone administration produced no significant changes in either glomerular filtration rate or renal plasma flow (Tables I and II). The subjects varied considerably in their control glomerular filtration rate values from $102 \mathrm{ml}$ per minute in M.U. to $213 \mathrm{ml}$ per minute in J.O.; a similar variation was noted in the renal plasma flow. Because no consistent alteration was observed in a given patient in these values after injection of the hormone, the marked changes in solute and electrolyte excretion to be described were not attributable to alterations in renal hemodynamics and therefore appeared to be due to the action of aldosterone on the renal tubules.

Effect on sodium and chloride excretion. Following aldosterone administration there was a delay of from 20 to 60 minutes before a significant reduction in sodium chloride excretion developed. During the first 20 to 60 minutes of aldosterone administration variable effects were observed, and in two of the seven studies a transient increase in sodium chloride excretion actually occurred in this early period (Figure 2, Tables I and II). Then, sodium chloride excretion was sharply reduced. The reduction reached a maximum 2 to 4 hours 
after the aldosterone administration was begun. The depressed sodium chloride excretion did not return toward the control values until 6 to 8 hours after completion of aldosterone administration.

The magnitude of the sodium retention (i.e., $\Delta \mathrm{U}_{\mathrm{Na}} \mathrm{V}$ from the control level) was the greatest in Subject J.O., who had the highest filtered load of sodium, and was least in Subject M.U. when he was sodium-depleted. Presumably, in this latter instance a maximal endogenous aldosterone effect was present $(19,20)$, and no further reduction in the $\mathrm{U}_{\mathrm{Na}} \mathrm{V}$ could be produced by aldosterone administration. In the other six studies the rate of sodium excretion was reduced by from 40 to 86.5 per cent of the control values, and the absolute rate of excretion was reduced by from 59 to $441 \mu \mathrm{Eq}$ per minute in these six studies.

A parallel but, in general, lesser reduction in chloride excretion was observed. In the first six of the seven experiments (Tables I and II), chloride excretion was reduced by from 21 to 66 per cent of the control values and the decrements in rate of chloride excretion ranged from 14 to 657 $\mu \mathrm{Eq}$ per minute in these six experiments. In one experiment (J.O. on $20 \mathrm{~g} \mathrm{NaCl}$ intake), the fall in chloride excretion after aldosterone actually exceeded the fall in sodium output by a considerable degree. The reason for this single observation remains obscure.

That the changes observed in sodium and chloride excretion were due to aldosterone and not to prolonged water diuresis is evident from data obtained in two control studies. Water diuresis was maintained for about 6 hours in two recumbent normal subjects. No significant changes in sodium, potassium or chloride excretion were observed during this period. In Subject O.G., whose protocol is presented in Table III, a stable water diuresis was established. Osmolar clearance fell slightly in the first 2 hours with stabilization at $2.7 \mathrm{ml}$ per minute while urine volume and free water clearance $\left(\mathrm{C}_{\mathrm{H}_{2} \mathrm{O}}\right)$ remained relatively unchanged. In a second normal subject, E.S., a similar course of results prevailed with an average urine flow of $17.6 \mathrm{ml}$ per minute in the first 190 minutes and $16.0 \mathrm{ml}$ per minute in the ensuing 160 minutes. Osmolar clearance fell slightly from an average of 2.8 to $2.5 \mathrm{ml}$ per minute during the same periods with a concomitant decline of free water clearance from 14.8 to 13.5 $\mathrm{ml}$ per minute. Average rates of electrolyte excretion in the first 190 minutes were: $\mathrm{Na}^{+}, 324$; $\mathrm{K}^{+}, 106$; and $\mathrm{Cl}^{-}, 424 \mu \mathrm{Eq}$ per minute; in the latter 160 minutes : $\mathrm{Na}^{+}, 411 ; \mathrm{K}^{+}, 70$; and $\mathrm{Cl}^{-}, 355$ $\mu \mathrm{Eq}$ per minute. These control studies are in agreement with the previous work of other investigators (21-23). Altogether, these results appear to exclude the possibility that the observed alterations in electrolyte excretion after aldosterone were simply a consequence of prolonged water diuresis.

Effect on potassium excretion and on urinary $p H$. In every experiment but one (M.U., saltdepleted) potassium excretion was at least transiently increased. The increased potassium excretion often preceded the sodium chloride retention

TABLE III

Detailed protocol of a typical control experiment *

\begin{tabular}{|c|c|c|c|c|c|c|c|c|c|c|c|}
\hline \multirow[b]{2}{*}{ Time } & \multirow[b]{2}{*}{$\mathrm{V}$} & \multirow[b]{2}{*}{$\mathrm{U}_{\mathrm{osm}}$} & \multirow[b]{2}{*}{$\mathrm{C}_{\text {osm }}$} & \multirow[b]{2}{*}{$\mathrm{C}_{\mathrm{H}_{2} \mathrm{O}}$} & \multirow[b]{2}{*}{$\mathrm{UNaV}_{\mathrm{Na}}$} & \multirow[b]{2}{*}{$\mathrm{UClC}_{\mathrm{Cl}}$} & \multirow[b]{2}{*}{$\mathrm{U}_{\mathrm{KV}}$} & \multicolumn{4}{|c|}{ Plasma } \\
\hline & & & & & & & & Osm & $\mathrm{Na}$ & $\mathrm{K}$ & $\mathrm{Cl}$ \\
\hline $0^{\min }$ & $\begin{array}{l}\mathrm{ml} / \mathrm{min} \\
1,500 \mathrm{ml} \\
5 \% \mathrm{Dext}\end{array}$ & $\begin{array}{l}\mu \mathrm{Osm} / \mathrm{ml} \\
\mathrm{H}_{2} \mathrm{O} \text { p.o., } \\
\text { trose and } \mathrm{w}\end{array}$ & $\begin{array}{l}\mathrm{ml} / \mathrm{min} \\
30 \mathrm{~min} \\
\text { water in }\end{array}$ & $\begin{array}{l}\mathrm{ml} / \mathrm{min} \\
\text { tes befo } \\
\text { usion at }\end{array}$ & $\begin{array}{l}\mu E q / \min \\
\text { e start of } \\
18 \mathrm{ml} / \mathrm{mi}\end{array}$ & $\begin{array}{l}\mu E q / \min \\
\text { infusion } \\
n \text {. }\end{array}$ & $\begin{array}{l}\mu E q / \min \\
\text { to recum }\end{array}$ & $\begin{array}{c}\mu O s m / m l \\
\text { nbent sub }\end{array}$ & $\begin{array}{l}\mu E q / m l \\
\text { ject. }\end{array}$ & $\mu E q / m l$ & $\mu E q / m l$ \\
\hline $\begin{array}{l}+23 \text { to } 67 \\
+67 \text { to } 105 \\
+105 \text { to } 149 \\
+149 \text { to } 209 \\
+209 \text { to } 231 \\
+231 \text { to } 252 \\
+252 \text { to } 280 \\
+280 \text { to } 317 \\
+317 \text { to } 340 \\
+340 \text { to }+360\end{array}$ & $\begin{array}{r}17.4 \\
18.2 \\
17.1 \\
18.2 \\
17.0 \\
17.2 \\
17.1 \\
17.1 \\
17.3 \\
14.8 \\
\text { Infusion }\end{array}$ & $\begin{array}{c}47 \\
45 \\
42 \\
42 \\
43 \\
43 \\
44 \\
43 \\
40 \\
45 \\
\text { completed }\end{array}$ & $\begin{array}{l}2.9 \\
3.4 \\
2.5 \\
2.7 \\
2.6 \\
2.7 \\
2.7 \\
2.7 \\
2.6 \\
2.5 \\
\text { d. }\end{array}$ & $\begin{array}{l}14.5 \\
14.8 \\
14.6 \\
15.5 \\
14.4 \\
14.5 \\
14.4 \\
14.4 \\
14.7 \\
12.3\end{array}$ & $\begin{array}{l}299 \\
184 \\
189 \\
212 \\
192 \\
211 \\
212 \\
204 \\
223 \\
170\end{array}$ & $\begin{array}{l}269 \\
212 \\
159 \\
175 \\
169 \\
208 \\
187 \\
186 \\
201 \\
154\end{array}$ & $\begin{array}{l}29 \\
33 \\
31 \\
25 \\
26 \\
24 \\
23 \\
25 \\
29 \\
34\end{array}$ & 287 & 146 & 4.5 & 103 \\
\hline
\end{tabular}

* Subject O.G., $71 \mathrm{~kg}$ white male on normal $\mathrm{NaCl}$ (approx. $6.0 \mathrm{~g} /$ day) intake. 


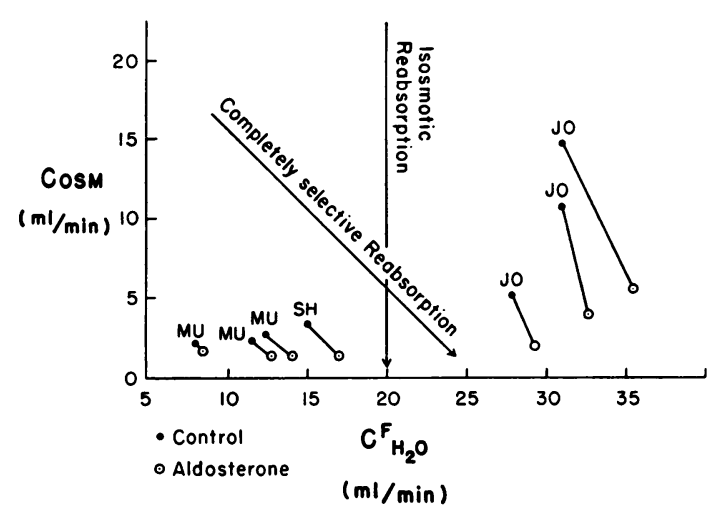

Fig. 3. EfFect of intravenous aldosterone on the RELATION OF OSMOLAR TO FREE WATER CLEARANCE DURING A maintained Water diUResis. Plotted from control periods taken at the height of water diuresis and from an average of two or three experimental periods at the peak of aldosterone effect. After aldosterone the decrement in osmolar clearance approaches or is equal to the increment in free water clearance in most of the studies. The rise in free water clearance occurs in the face of a falling osmolar clearance. The findings suggest that aldosterone abstracts sodium chloride from the urine without water.

and persisted during the periods of maximal sodium retention in only four of the seven experiments (Tables I and II ; Figures 1 and 2).

The magnitude of the increased potassium excretion produced by aldosterone $\left(\Delta \mathrm{U}_{\mathrm{K}} \mathrm{V}\right)$ was small, ranging from +12 to $+40 \mu \mathrm{Eq}$ per minute or from +17 to +30 per cent of the control values. The increments in $\mathrm{K}^{+}$excretion were of similar degree in all studies and were of considerably lesser magnitude than the decrements observed in sodium chloride excretion.

The urinary $\mathrm{pH}$ was observed to fall following aldosterone excretion (Tables I and II). The average observed fall was $0.38 \mathrm{pH}$ units at the peak of the action of the hormone on total solute excretion.

Effect on urine flow, total solute clearance and free water excretion. In all studies aldosterone was administered only after the peak of water diuresis had been achieved. The control rate of urine flow varied considerably in different subjects from 10 to $45 \mathrm{ml}$ per minute. These individual variations in urine flow seemed to be related to the variations in filtered load of solute (24). After aldosterone administration, the urine flow either did not change or showed a slight decrease, such as that which occurs in prolonged water diuresis. Therefore, the effects of aldosterone were observed during the descending limb of water diuresis.

The changes in total solute excretion after aldosterone paralleled the changes in sodium excretion both in magnitude and in phase. Thus, after an initial delay of from 20 to 60 minutes a progressive and marked reduction in urinary osmolarity ensued reaching a nadir 2 to 4 hours after the aldosterone administration. Urinary osmolarity fell to levels well below that which would be expected from water diuresis alone (21-23) (20 $\mu$ Osm per $\mathrm{ml})$. Thus, aldosterone facilitated the formation of an extremely dilute urine with an increased urine/plasma osmolar gradient. The urine/plasma sodium concentration gradient increased markedly in like manner.

As was the case with sodium chloride excretion, the total solute excretion did not fall appreciably in the sodium-depleted subject. However, in the other six studies total solute concentration was reduced by from 49 to 67 per cent of control values. A similar reduction in the total solute clearance $\left(\mathrm{C}_{o \mathrm{osm}}\right)$ was thus observed.

Since the urine flow did not change appreciably while the osmolar clearance decreased markedly, an increase in free water clearance was produced by aldosterone. In the first six experiments, the free water clearance was increased by from 1.1 to $4.3 \mathrm{ml}$ per minute, but in the sodium-depleted subject, M.U., the observed changes were again slight. Since the urine flow was not rising, the calculated increases in free water cannot be attributed to an increasing water diuresis, and because solute excretion was falling, they cannot be the result of an increased solute load (24). Hence, these results imply the hypertonic abstraction of solute from the urine, i.e., reabsorption of solute unaccompanied by isosmotic amounts of water.

In Figure 3 the relationship between the osmolar clearance and the free water clearance before and after aldosterone for all seven experiments is plotted. It can be seen that after aldosterone the fall in solute clearance $\left(\Delta \mathrm{C}_{\mathrm{osm}}\right)$ is equal to, or almost equal to, the rise in free water clearance $\left(\Delta \mathrm{C}_{\mathrm{I}_{2} \mathrm{O}}\right)$. In fact, in four studies of Subjects M.U. and S.H., $1 \mathrm{ml}$ of free water was added to the urine for each milliliter of urine cleared of solute. This implies that aldosterone 
caused the virtually totally selective abstraction of solute without water from the tubular urine.

Relationship of changes in sodium and chloride clearances to changes in osmolar clearance. Because in normal individuals sodium and chloride are the major osmolar constituents of urine and plasma and comprise the bulk of the filtered load, these solutes are the only ones available for tubular reabsorption in amounts sufficient to account for most of the free water generated during water diuresis (13). Therefore, one might assume that the changes in osmolar and free water clearance produced by aldosterone were due to the effects of the hormone on sodium (and chloride) ; and, in fact, in all experiments, changes in $\mathrm{U}_{\mathrm{Na}} \mathrm{V}$ and in $\mathrm{U}_{\mathrm{Cl}} \mathrm{V}$ closely paralleled changes in $\mathrm{U}_{\mathrm{osm}} \mathrm{V}$. Aldosterone caused alterations in sodium and chloride excretion of such magnitude that, for the most part, alterations in $\mathrm{C}_{\mathrm{osm}}$ produced by the hormone can be interpreted largely in terms of these ions.

In an effort to relate graphically the effect of aldosterone on sodium excretion to that on solute excretion (Figure 4 ), twice the $\mathrm{C}_{\mathbf{N a}}{ }^{2}$ caused by the hormone has been plotted against the $\mathrm{C}_{\text {osm }}$ caused by the aldosterone for all experiments, with a resultant linear relationship. It can be seen that the changes of $\mathrm{C}_{\mathrm{osm}}$ and thus of free water can be interpreted to be mainly a result of the effect of aldosterone on sodium (with equivalent anions). Hence, it can be concluded that aldosterone produced a fall in $\mathrm{C}_{\mathrm{osm}}$ and a rise in $\mathrm{C}_{\mathrm{H}_{2} \mathrm{O}}$ by the abstraction of salt from a clistal portion of the nephron.

Effect on urea excretion. In all experiments, the urea clearance declined gradually with no acute change observed following aldosterone administration. These data are not given in the tables.

\section{DISCUSSION}

A number of the observations made in the present study appear to confirm and extend the

${ }^{2}$ For a $\Delta \mathrm{C}_{\mathrm{osm}}$ of $1 \mathrm{ml}, 1 \times \mathrm{P}_{\mathrm{osm}}$ (approximately 280 $\mu \mathrm{Osm})$ was abstracted from tubular lumen. For a $\Delta \mathrm{C}_{\mathrm{Na}}$ of $1 \mathrm{ml}$ then, $1 \times \mathrm{P}_{\mathrm{Na}}$ (approximately $140 \mu \mathrm{Eq}$ ) of $\mathrm{Na}^{+}$ was abstracted. Each microequivalent is an osmotically active particle. In abstraction of $\mathrm{Na}^{+}$an equivalent number of anions, also osmotically active particles, was removed. Hence, to relate $\Delta C_{\mathrm{Na}}$ to $\Delta \mathrm{C}_{\mathrm{osm}}$, one must multiply $\Delta \mathrm{C}_{\mathrm{Na}} \times 2$. findings of other investigators. Thus, the delayed onset of action $(3,7,25-29)$, the lack of effect on renal hemodynamics $(2,28,30)$, the sodium and chloride retention, and the kaliuresis of aldosterone (1-13) have all been described under a variety of experimental and clinical conditions.

In the present study a latent period of about 20 to 60 minutes was observed before there was any demonstrable effect of the hormone on sodium excretion. The peak effect occurred in 2 to 4 hours, and the action lasted for as long as 6 to 8 hours after administration. In previous studies of man, other investigators have also noted a similar latent period and a similar duration of activity $(3,7,25)$. Moreover, Barger, Berlin and Tulenko (26) and Ganong, Mulrow and Hollinger $(31,32)$, utilizing renal artery infusions, and Crabbé (27), utilizing an isolated toad bladder, have also noted the delayed onset of action of the hormone.

Mineralocorticoids such as desoxycorticosterone and aldosterone, in short-term studies, do not appear to alter renal hemodynamic function either in experimental animals $(28-33)$ or in man (3436). In the present study aldosterone did not produce significant changes in the renal plasma flow or in the glomerular filtration rate. There-

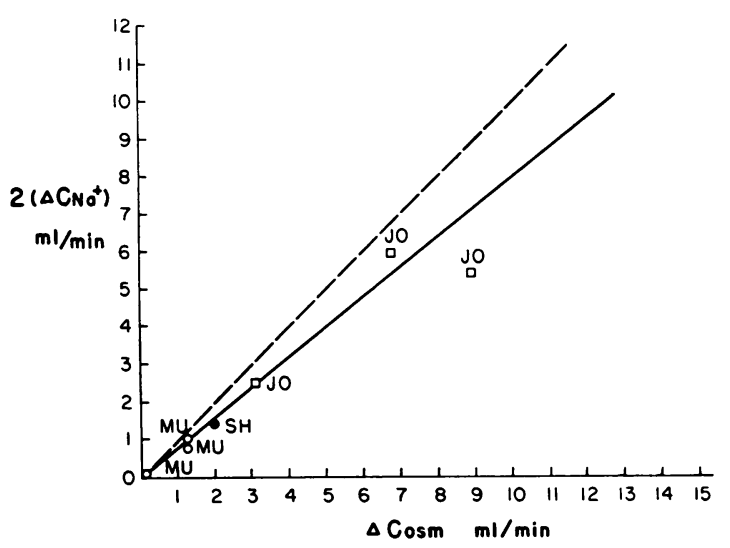

Fig. 4. Relationship between the change in osMOLAR CLEARANCE AND TWO TIMES THE CHANGE IN SODIUM Clearance PRODUCEd by aldosterone. Two times the decrement in sodium clearance after aldosterone administration is plotted against the corresponding decrement in osmolar clearance produced by the hormone. The plot illustrates that the observed changes in osmolar clearance produced by the hormone are largely accounted for by a similar change in sodium reabsorption with attendant anion. 
fore, it would appear that the observed effects on electrolyte and water excretion are the result of induced alterations in the activity of tubular transport systems.

The intravenous administration of aldosterone caused increased tubular reabsorption of sodium chloride and a kaliuresis. The increased potassium excretion often began prior to salt retention, was relatively small in degree, and at times had ceased before the sodium retention had reached its peak. Similar effects of aldosterone have been described both during acute administration $(2,7$, $25,26,31-33)$ and in more prolonged balance studies $(1,3-6,37)$.

In the present study aldosterone usually caused sodium retention in excess of chloride, confirming the results of August and Nelson (7), who administered aldosterone intravenously with isotonic saline infusions. It thus appears that aldosterone acted to augment the active renal tubular reabsorption of sodium ion with chloride. Precedent for the stimulation of active sodium transport by aldosterone has been found in vitro by Crabbé (27), using an isolated toad bladder.

According to present concepts (38), filtered potassium is completely reabsorbed before the potassium destined for excretion is secreted into the tubular urine by a distal $\mathrm{K}^{+}$for $\mathrm{Na}^{+}$ion exchange process. However, while the kaliuresis observed in these experiments may have resulted from an acceleration of this ion exchange mechanism, considerable evidence indicates that the predominant effect of aldosterone-i.e., to cause sodium and chloride reabsorption-occurred independently of, and at a different locus in the distal nephron from the $\mathrm{K}^{+}$for $\mathrm{Na}^{+}$ion exchange process. Thus, the kaliuresis in general was not temporally related to the sodium retention, the magnitude of the kaliuresis was far less than the sodium retention, and the degree of kaliuresis in each subject was not related to the corresponding degree of sodium retention. Ion exchange, $\mathrm{Na}^{+}$for $\mathrm{K}^{+}$, does not explain the significant chloride retention which occurred concomitant with sodium reabsorption. Furthermore, ion exchange does not explain the reduced osmolarity of the urine after administration of the hormone, since the observed decrements in $\mathrm{NaCl}$ excretion were, in fact, accompanied by comparable reductions in total solute excretion.

The present study demonstrates that aldosterone can cause the abstraction of sodium chloride without water from the tubular urine, a finding which has not been reported heretofore. ${ }^{3}$ During maintained water diuresis aldosterone caused the removal of sodium chloride from the urine, producing a fall in osmolar clearance while urine flow was maintained; this resulted in a concomitant rise in free water clearance. For Subjects S.H. and M.U., the relationships between solute abstraction and free water formation were such (Figure 3) as to suggest that salt was abstracted virtually without water. However, in Subject J.O. the increment in free water clearance was less than the decrement in osmolar clearance indicating that, in this subject, in addition to selective sodium chloride reabsorption, some additional isosmotic reabsorption may also have been induced.

Previous studies have indicated $(24,39,40)$ that, during water diuresis, there is a direct relationship between solute excretion and free water clearance, a rise in $\mathrm{C}_{\text {osm }}$ resulting in a rise in $\mathrm{C}_{\mathrm{H}_{2} \mathrm{O}}$. Therefore, the rise in free water clearance noted after aldosterone may have more significance because it occurred in the face of a falling solute excretion. Further, because the hormone was administered only after a peak of water diuresis was achieved, when urine flow was either stable or declining, the increment in free water excretion after aldosterone administration cannot be simply the result of an increasing water diuresis.

Because aldosterone facilitates net abstraction of sodium chloride without water from the urine, it thus appears to act in the nephron at a locus distal to the site of isosmotic reabsorption. The concept that free water is formed in the more distal tubular segments by selective reabsorption of solute without wăter is well supported by a number of studies (14-17). Micropuncture studies have shown that in the proximal tubule, sodium reabsorption is isosmotic (14-16), while fluid from the early distal tubule has been found to be hypotonic regardless of whether the final urine is hypo-or hyperosmotic (16). Vander and coworkers, using a stop-flow technique (41), have reported that in adrenalectomized dogs, aldosterone increased the maximal concentration gra-

\footnotetext{
${ }^{3}$ Dingman and associates measured the osmolar clearance during infusion of aldosterone. However, water diuresis was not maintained in these studies (2).
} 
dient for sodium which could be developed between the plasma and distal tubular urine.

Because the hormone caused a distal abstraction of salt without water from the urine, an increased plasma/urine sodium concentration gradient was formed and the urine became more dilute. The results thus suggest that aldosterone is concerned with the production of a hypotonic urine. Inferential support for this role of aldosterone in urinary dilution may be derived from previous studies of electrolyte and water metabolism in adrenalectomized dogs $(29,30,42,43)$ and in patients with adrenal or pituitary insufficiency $(35,44,45)$. In this group a characteristic picture is seen with low glomerular filtration, increased loss of sodium chloride (43), and a deficient ability to excrete a water load (47). Mineralocorticoid (46) alone, while promoting salt retention, does not repair the defect in water excretion. Cortisol $(20,30,44,46)$ increases the filtration rate, increases filtered sodium load, and allows more salt to be reabsorbed from the distal tubule with the production of free water and the excretion of a more dilute urine. However, this process is not very efficient, and although the ability to excrete water is improved, this occurs at the expense of substantial urinary wastage of sodium chloride. With cortisol plus a mineralocorticoid $(35,45)$, solute (i.e., $\mathrm{NaCl})$ can be more efficiently removed from the distal tubule with both the conservation of sodium and the simultaneous production of a potentially more hypotonic urine for excretion. A similar function for the endogenous adrenal mineralocorticoid hormone, aldosterone, is implied by these data.

\section{SUM MARY}

Aldosterone ( $2 \mathrm{mg} d, l$-monoacetate) was given intravenously during a maintained water diuresis to normal subjects. No significant changes in glomerular filtration rate or in renal plasma flow were observed.

After a latent period of from 20 to 60 minutes, during which natriuresis actually occurred in two of the seven studies, the hormone produced a marked reduction in sodium with a lesser reduction in chloride excretion. The peak of this effect occurred in 2 to 4 hours.

Aldosterone also increased potassium excretion, but this effect was often temporally dissociated from the major action of the hormone, which was to cause sodium and chloride retention.

After aldosterone administration urine flow either did not change or declined slightly; the osmolar clearance was reduced, and hence the free water clearance was increased. In some of the studies, the decrement in osmolar clearance approached or was equal to the increment in free water clearance produced by the hormone.

The results suggest that, under circumstances of water diuresis, aldosterone can promote net abstraction of sodium chloride from the urine, virtually without water, in a distal portion of the renal tubule.

The action of aldosterone results in the creation of an increased plasma/urine sodium concentration gradient and the formation of a more hypotonic urine. It is therefore suggested that the hormone plays a role in urinary dilution.

\section{REFERENCES}

1. Mach, R. S., Fabre, J., Duckert, A., Borth, R., and Ducommun, P. Action clinique et métabolique de l'aldostérone (electrocortine). Schweiz. med. Wschr. 1954, 84, 407.

2. Dingman, J. F., Finkenstaedt, J. T., Laidlaw, J. C., Renold, A. E., Jenkins, D., Merrill, J. P., and Thorn, G. W. Influence of intravenously administered adrenal steroids on sodium and water excretion in normal and Addisonian subjects. Metabolism 1958, 7, 608.

3. Thorn, G. W., Sheppard, R. H., Morse, W. I., Reddy, W. J., Beigelman, P. M., and Renold, A. E. Comparative action of aldosterone and 9-alphafluorohydrocortisone in man. Ann. N. Y. Acad. Sci. 1955, 61, 609.

4. August, J. T., Nelson, D. H., and Thorn, G. W. Response of normal subjects to large amounts of aldosterone. J. clin. Invest. 1958, 37, 1549.

5. Desaulles, P. Comparison of the effects of aldosterone, cortexone and cortisol on adrenalectomized rats under various salt loads in An International Symposium on Aldosterone, A. F. Muller and C. M. O'Connor, Eds. Boston, Little, Brown, 1958, p. 29.

6. Kekwick, A., and Pawan, G. L. S. Oral aldosterone. Effect in a case of Addison's disease. Lancet 1954, 2, 162 .

7. August, J. T., and Nelson, D. H. The dual action of aldosterone on renal sodium reabsorption in normal subjects. Clin. Res. 1959, 7, 274.

8. Conn, J. W., and Louis, L. H. Primary aldosteronism, a new clinical entity. Ann. intern Med. 1956, 44, 1. 
9. Holten, C., and Peterson, V. P. Malignant hypertension with increased secretion of aldosterone and depletion of potassium. Lancet 1956, 2, 918.

10. VanBuchem, F. S. P., Doorenbos, H., and Elings, H. S. Primary aldosteronism due to adrenocortical hyperplasia. Lancet 1956, 2, 335.

11. Laragh, J. H., Ulick, S., Januszewicz, V., Deming, Q. B., Kelly, W. G., and Lieberman, S. Aldosterone secretion and primary and malignant hypertension. J. clin. Invest. 1960, 39, 1091.

12. Heinemann, H. O., Demartini, F. E., and Laragh, J. H. The effects of chlorothiazide on renal excretion of electrolytes and free water. Amer. J. Med. 1959, 26, 853.

13. Smith, H. W. Principles of Renal Physiology. New York, Oxford Univ. Press, 1956.

14. Walker, A. M., Bott, P. A., Oliver, J., and MacDowell, M. L. Collection and analysis of fluid from single nephrons of the mammalian kidney. Amer. J. Physiol. 1941, 134, 580.

15. Wirz, H. Location of antidiuretic action in the mammalian kidney in The Neurohypophysis, H. Heller, Ed. New York, Academic Press, 1957, p. 157.

16. Gottschalk, C. W., and Mylle, M. Micropuncture study of the mammalian urinary concentrating mechanism; evidence for the countercurrent hypothesis. Amer. J. Physiol. 1959, 196, 927.

17. Wesson, L. G., Jr., and Anslow, W. P., Jr. Effect of osmotic and mercurial diuresis on simultaneous water diuresis. Amer. J. Physiol. 1952, 170, 255.

18. Van Slyke, D. D., and Cullen, G. E. The determination of urea by the urease method. J. biol. Chem. 1916, 24, 117.

19. Duncan, L. E., Jr., Liddle, G. W., and Bartter, F. C. The effect of changes in body sodium on extracellular fluid volume and aldosterone excretion by normal and edematous men. J. clin. Invest. 1956, 35, 1299.

20. Johnson, B. B., Lieberman, A. H., and Mulrow, P. J. Aldosterone excretion in normal subjects depleted of sodium and potassium. J. clin. Invest. 1957, 36, 757.

21. Bucht, H., Ek, J., Josephson, B., Thomasson, B., Varnauskas, E., and Werkö, L. Rapid infusion and renal function. Clin. Sci. 1956, 15, 617.

22. Ladd, M. Effect of prehydration upon renal excretion of sodium in man. J. appl. Physiol. 1951, 3, 603.

23. Rosenbaum, J. D., Nelson, W. P., III, Strauss, M. B., Davis, R. K., and Rossmeisl, E. C. Variation in the diuretic response to ingested water related to the renal excretion of solutes. J. clin. Invest. 1953, 32, 394.

24. Kleeman, C. R., Epstein, F. H., and White, C. The effects of variations in solute excretion and glomerular filtration on water diuresis. J. clin. Invest. 1956, 35, 749.

25. Liddle, G. W., Cornfield, J., Casper, A. G. T., and Bartter, F. C. The physiological basis for a method of assaying aldosterone in extracts of human urine. J. clin. Invest. 1955, 35, 1410.

26. Barger, A. C., Berlin, R. D., and Tulenko, J. F. Intrarenal arterial infusion of aldosterone and antidiuretic hormone in the normal and adrenalectomized dog: Electrolyte and water excretion. Fed. Proc. 1957, 16, 6.

27. Crabbé, J. Stimulation of active sodium transport across the isolated toad bladder by aldosterone in vitro. Clin. Res. 1960, 8, 227.

28. Green, D. M., Farah, A., and Klemperer, W. W. Mechanisms of desoxycorticosterone action: Renal effects of the water-soluble glycoside. Endocrinology 1950, 47, 281.

29. Roberts, K. E., and Pitts, R. F. The influence of cortisone on renal function and electrolyte excretion in the adrenalectomized dog. Endocrinology 1952, 50, 51.

30. Garrod, O., Davies, S. A., and Cahill, G., Jr. The action of cortisone and desoxycortisone acetate on glomerular filtration rate and sodium and water exchange in the adrenalectomized dog. J. clin. Invest. 1955, 34, 761.

31. Ganong, W. F., Mulrow, P. J., and Hollinger, G. W. Sodium and potassium excretion after injection of aldosterone into renal artery. Fed. Proc. 1957, 16, 44.

32. Ganong, W. F., and Mulrow, P. J. Rate of change in sodium and potassium excretion after injection of aldosterone into the aorta and renal artery of the dog. Amer. J. Physiol. 1958, 195, 337.

33. Barger, A. C., Muldowney, F. P., and Liebowitz, M. R. Role of the kidney in the pathogenesis of congestive heart failure. Circulation 1959, 20, 273.

34. Huffman, E. R., Wilson, G. M., Jr., Clark, G. M., and Smyth, C. J. The acute renal effects of 9-alpha fluorohydrocortisone in human subjects with intact adrenals. J. Lab. clin. Med. 1956, 47, 747.

35. Doorenbos, H., Streeten, D. H. P., and Conn, J. W. A water diuretic effect of mineralocorticoids in hydrocortisone-treated adrenal insufficiency. Clin. Res. 1958, 6, 255.

36. Barnett, H. L., and McNamara, H. Electrolyte balances in a male infant with adrenocortical insufficiency and virilism. The effect of desoxycorticosterone acetate and salt therapy with special reference to potassium. J. clin. Invest. 1949, 28, 1498.

37. Prunty, F. T. G., McSwiney, R. R., Mills, I. H., and Smith, M. A. The effects of aldosterone in Addison's disease and adrenal pseudo hermaphroditism. Lancet 1954, 2, 620.

38. Berliner, R. W. Ion exchange mechanisms in the nephron. Circulation 1960, 21, 892.

39. Orloff, J., Wagner, H. N., Jr., and Davidson, D. G. The effect of variations in solute excretion and 
vasopressin dosage on the excretion of water in the dog. J. clin. Invest. 1958, 37, 458.

40. De Wardener, H. E., and del Greco, F. The influence of solute excretion rate on the production of a hypotonic urine in man. Clin. Sci. 1955, 14, 715.

41. Vander, A. J., Malvin, R. L., Wilde, W. S., Lapides, J., Sullivan, L. P., and McMurray, V. M. Effects of adrenalectomy and aldosterone on proximal and distal tubular sodium reabsorption. Proc. Soc. exp. Biol. (N. Y.) 1958, 99, 323.

42. Loeb, R. F., Atchley, D. W., Benedict, E. M., and Leland, J. Electrolyte balance studies in adrenalectomized dogs with particular reference to the excretion of sodium. J. exp. Med. 1933, 57, 775.

43. Roemmelt, J. C., Sartorius, O. W., and Pitts, R. F. Excretion and reabsorption of sodium and water in the adrenalectomized dog. Amer. J. Physiol. 1949, 159, 124.

44. Kleeman, C. R., Maxwell, M. H., and Rockney, R. E. Mechanisms of impaired water excretion in adrenal and pituitary insufficiency. I. The role of altered glomerular filtration rate and solute excretion. J. clin. Invest. 1958, 37, 1799.

45. Knopf, R., Streeten, D. H. P., and Conn, J. W. Mechanism of the water-retaining effect of mineralocorticoids. Clin. Res. 1960, 8, 230.

46. Raisz, L. G., McNeely, W. F., Saxon, L., and Rosenbaum, J. D. The effects of cortisone and hydrocortisone on water diuresis and renal function in man. J. clin. Invest. 1957, 36, 767.

47. Slessor, A. Studies concerning the mechanism of water retention in Addison's disease and in hypopituitarism. J. clin. Endocr. 1951, 11, 700.

\section{SPECIAL NOTICE TO SUBSCRIBERS}

Post Offices will no longer forward the Journal when you move. Please notify The Journal of Clinical Investigation, Business Office, 333 Cedar Street, New Haven 11, Conn., at once when you have a change of address, and do not omit the zone number if there is one. 